\title{
Substorm dynamics revealed by ground observations of two-dimensional auroral structures on 9 October 2000
}

\author{
J. Liang ${ }^{1, *}$, E. F. Donovan ${ }^{2}$, G. J. Sofko ${ }^{1}$, and T. Trondsen ${ }^{2}$ \\ ${ }^{1}$ Institute of Space and Atmospheric Studies, University of Saskatchewan, Saskatoon, Canada \\ ${ }^{2}$ Department of Physics and Astronomy, University of Calgary, Calgary, Canada \\ *now at: Canadian Space Agency, 6767 route de l'Aéroport, Saint-Hubert, Québec, Canada
}

Received: 2 June 2005 - Revised: 7 October 2005 - Accepted: 14 November 2005 - Published: 23 December 2005

\begin{abstract}
Multi-instrument observations of a small substorm event on 9 October 2000 provide, with high time resolution, two-dimensional information about substorm dynamics. A sequence of three optical intensifications, each associated with a Pi2 burst, were found, in which the third auroral intensification marked the onset of a small substorm. All three intensifications originated close to midnight, but evolved progressively eastward. Within each of the three optical intensifications, a few azimuthally-spaced patches appeared, the first one near midnight and the subsequent patches successively eastward in the postmidnight sector, providing evidence for drift wave activity in the neargeosynchronous-orbit plasma sheet (NGOPS). The SuperDARN measurements reveal the development of eastward electric fields at NGOPS latitude within each Pi2 burst interval. These observations can be interpreted as supporting the drift-Alfvén-ballooning (DAB) mode instability and its role in substorm expansion at NGOPS.
\end{abstract}

Keywords. Ionosphere (Auroral ionosphere) - Magnetospheric physics (Storms and substorms, Plasma waves and instabilities)

\section{Introduction}

Plasma macroinstabilities occurring in the neargeosynchronous-orbit plasma sheet (NGOPS) are a key component of the near-Earth initiation scenario of substorms (Lui, 1996; 2001). Suggestions for the particular type of NGOPS instability include the cross-field current instability (Lui et al, 1991), the drift-Alfvén-ballooning (DAB) instability (Roux et al., 1991), the shear flow ballooning instability (Samson et al., 1996), and the magnetosphere-ionosphere coupling feedback instability (Kan, 1993). The ballooning instability initially proposed by Roux et al. (1991) was criticized by Ohtani and Tamao (1993) etc. In 19 out of 22

Correspondence to: J. Liang

(liang@dansas.usask.ca) events they studied, when taking into account the stabilizing effects of plasma compressibility, they claimed that a necessary condition for the ballooning instability was not satisfied. However, Liu (1997) pointed out that Ohtani and Tamao (1993) erred in their handling of the parallel momentum equation. A correction of this error leads to a much increased likelihood of ballooning instability occurrence in a realistic plasma sheet. Two-fluid MHD simulations by $\mathrm{Pu}$ et al. (1997) showed two unstable drift-ballooning mode (DBM) solutions, namely DBM1 (conventional ballooning mode) and DBM2 (Alfvénic ballooning mode), of which the latter is more easily excited in the late substorm growth phase. Using GEOS 2 observations they found that the necessary conditions for DBM2 were fulfilled in 14 out of 16 events. Ivanov and Pokhotelov (1987) and Ivanov et al. (1992) showed that the introduction of plasma pressure gradients which are not aligned with the curvature vector of the magnetic field would facilitate the growth of the flute/ballooning instability. According to their theory, if there exists a compression of the NGOPS plasma in the midnight sector, then the wave vector associated with the instability is westward in the evening and eastward in the morning. Elphinstone et al. (1995) studied the azimuthally spaced auroral forms (AAFs) observed during auroral substorms and suggested that the AAFs are associated with this modified drift ballooning instability. The CRRES satellite observations provided clear evidence which related the NGOPS instability, in particular the DAB mode, to the substorm expansion phase (EP) onset (Yeoman et al., 1994; Maynard et al., 1996; Erickson et al., 2000). Erickson et al. (2000) suggested that the amplitude of polarization electric field oscillations in the drift wave increases with the growth of the instability, causing eastward excursions of the total electric field. During such an eastward excursion of net E-field, the drift wave couples to the Alfvén mode, causing energy transfer to the ionosphere and leading to a substorm expansion.

The study in the present paper is a continuation of the work presented in Liang et al. (2004) (hereafter referred as 
Table 1. Magnetometer stations used in this paper.

\begin{tabular}{lllllll}
\hline Station Name & Code & $\begin{array}{l}\text { Geo. Lat } \\
\left({ }^{0} \mathrm{~N}\right)\end{array}$ & $\begin{array}{l}\text { Geo. Lon. } \\
\left({ }^{0} \mathrm{E}\right)\end{array}$ & $\begin{array}{l}\text { AACGM Lat. } \\
\left({ }^{0} \mathrm{~N}\right)\end{array}$ & $\begin{array}{l}\text { AACGM Lon. } \\
\left({ }^{0} \mathrm{~N}\right)\end{array}$ & $\begin{array}{l}\text { MLTMN } \\
\text { UT }\end{array}$ \\
\hline Pinawa & PINA & 50.20 & 263.96 & 60.59 & -29.41 & $6: 40$ \\
Gillam & GILL & 56.38 & 265.36 & 66.71 & -28.20 & $6: 35$ \\
Fort Churchill & FCHU & 58.76 & 265.92 & 69.01 & -27.75 & $6: 34$ \\
Eskimo Point & ESKI & 61.11 & 265.95 & 71.21 & -28.22 & $6: 35$ \\
Rankin Inlet & RANK & 62.82 & 267.89 & 72.91 & -25.34 & $6: 26$ \\
Rabbit Lake & RABB & 58.22 & 256.32 & 67.39 & -42.48 & $7: 25$ \\
Fort Smith & FSMI & 60.02 & 248.05 & 67.71 & -54.90 & $8: 11$ \\
\hline
\end{tabular}

LJ04). In LJ04, we analyzed a small substorm event that occurred on 9 October 2000 during dominantly IMF $B_{y}+$, $B_{z}+$ conditions, focusing on the global ionospheric convection and its association with the solar wind variations and the substorm evolution. In the current paper, we will focus on the details of the auroral variations during the substorm event and on their possible explanation in terms of the neargeosynchronous onset substorm scenario, in particular the DAB mode instabilities. With high temporal resolution and extensive spatial coverage, the origin and subsequent evolution of each auroral activation during the event sequence are investigated. Azimuthally-spaced auroral patches that appeared successively from midnight toward the morning sector were identified, and are interpreted as evidence of DAB instabilities occurring in the near-midnight NGOPS. The optical, magnetic and HF radar signatures of the event are found to be consistent with the DAB substorm scenario developed by Maynard et al. (1996) and Erickson et al. (2000), based upon the CRRES observations.

\section{Description of the equipment}

The main instruments for this study are the NORSTAR (NORthern Solar Terrestrial ARray) all-sky imager at Rankin Inlet, the SuperDARN (Super Dual Auroral Radar Network) HF radars at Saskatoon and Kapuskasing, the CANOPUS (Canadian Auroral Network for the OPEN Program Unified Study) magnetometers and riometers, and the CANOPUS meridian scanning photometers (MSPs) at Gillam and Fort Smith. The coordinates and the UT times of local magnetic midnight at the relevant stations are listed in Table 1.

The SuperDARN radars (Greenwald et al., 1995) measure the coherent backscattered power and Doppler spectra associated with decameter-scale field-aligned irregularities in the ionospheric $E$ and $F$-regions. Each radar employs a single beam which is directed to 16 successive angular positions, with successive beams separated by $3.24^{\circ}$. The wedgeshaped field-of-view (FoV) is thus about $52^{\circ}$ wide in for each radar, and the sequence of 16 beams is normally covered in a 2-min scan. The most important parameter observed by the radar is the Doppler velocity of the irregularities, which at $F$-region heights yields a measure of the line-of-sight convective drift of the plasma, given by $\mathbf{v}=\mathbf{E} \times \mathbf{B} / B^{2}$, where $\mathbf{E}$ is the electric field and $\mathbf{B}$ is the geomagnetic field. By combining the measurements from one or more pairs of radars with overlapping FoVs, a large-scale map of the two-dimensional convection velocity in a plane perpendicular to $\mathbf{B}$ can be obtained every two minutes (or one minute in fast scan mode).

NORSTAR (NORthern Solar Terrestrial ARray) is an optical and radio facility designed to remotely sense auroral precipitation on a continental scale. Each NORSTAR allsky imager (NASI) collects data at four auroral wavelengths $(471.3,557.7,630.0,486.1 \mathrm{~nm})$, with an acquisition interval of $10-60$ s per image. The NASI at Rankin Inlet, which provides the best coverage for collaborative studies with the Saskatoon-Kapuskasing radar pair, is used in this paper.

Auroral data are also taken from the meridian scanning photometers (MSPs) at Gillam and Fort Smith. The instruments are eight-channel filter wheel photometers. Five of the eight channels measure auroral emissions $(470.9 \mathrm{~nm}$, $486.1 \mathrm{~nm}$ twice, $557.7 \mathrm{~nm}$ and $630.0 \mathrm{~nm}$ ). Each MSP measures the optical emission along its meridian scan line with 1-minute resolution, over seventeen $0.5^{\circ}$ latitude bins (for the emission height at $110 \mathrm{~km}$ ), with the middle bin centered above the station (bin 0 is the most poleward and bin 16 the most equatorward).

To complement the study, the data from the CANOPUS magnetometer, meridian scanning photometers (MSPs) and riometer arrays are also used. Figure 1 shows the locations of the magnetometer sites (black dots), the circular FoV of the Rankin Inlet NASI for the $630 \mathrm{~nm}$ oxygen red line, assuming a $215 \mathrm{~km}$ emission height (the reason for choosing that height will be discussed below), the meridian scan lines of the MSPs at Gillam and Fort Smith (denoted by thick lines), and the centerlines of the 16 SuperDARN beams from Saskatoon and from Kapuskasing. The magnetic latitudes shown on the background geographic map are AACGM (Altitude Adjusted Corrected GeoMagnetic) coordinates (Baker and Wing, 1989). At each CANOPUS magnetometer station, a zenith riometer with a 4-element antenna and a single 


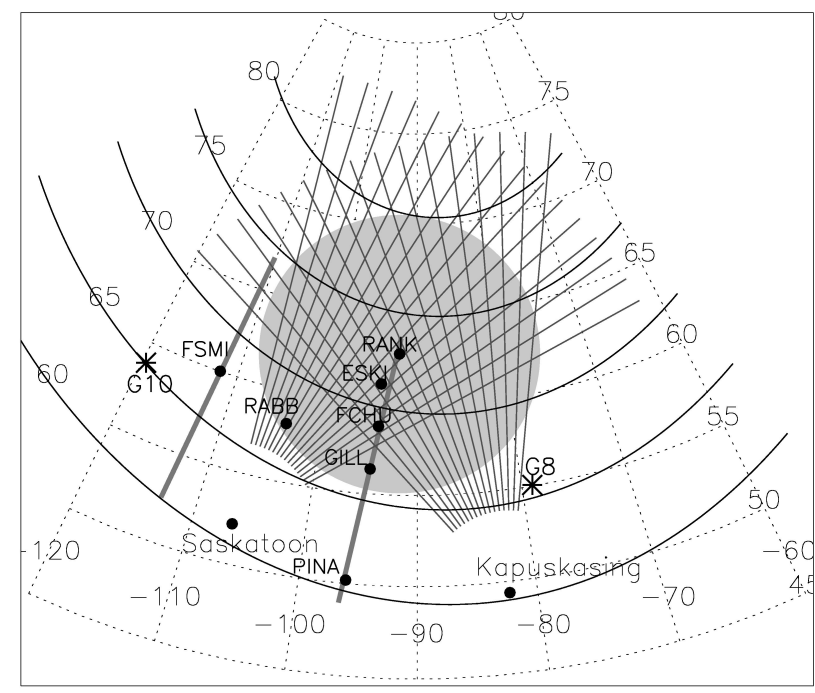

Fig. 1. Map of the FoVs of the SuperDARN radars at Saskatoon and Kapuskasing, and of the NORSTAR imager at Rankin Inlet (for red-line emission at assumed height of $215 \mathrm{~km}$ angles from 0 to $80^{\circ}$ from nadir). CANOPUS magnetometers listed in Table 1 are shown in black dots. The scan lines of the Gillam and Fort Smith MSPs are shown in gray lines. The asterisks labeled G8 and G10 denote respectively the ionospheric footprints of the GOES-8 and GOES10 satellites calculated from the T89c model (Tsyganenko, 1989) with $K_{p}=1$.

$150 \mathrm{kHz}$ broadband receiver is also deployed. The riometer measures the cosmic radio noise absorption at $30 \mathrm{MHz}$. This absorption can occur either in the lower ionospheric $E$-region due to the anomalous electron heating by plasma wave instabilities (Schlegel and St.-Maurice, 1981), or in the $D$-region due to hard electron $(>40 \mathrm{keV})$ precipitation (Penman et al., 1979). Both of these processes are normally associated with auroral intensifications (Stoker et al., 1996; 1997).

\section{The multi-instrument observations}

3.1 CANOPUS magnetometer, riometer and photometer observations

In terms of magnetic activity, 9 October was in fact the fourth quietest day of the month. The Kp index values during the first three 3-h UT intervals were $1-, 0+$ and $0+$. However, as described in LJ04 (Fig. 2 in the paper), a sequence of three well-defined magnetic and optical auroral activations were found. The first two activations are classified as pseudobreakups, while the last and strongest activation is classified as a small substorm expansive phase (EP). The reason for such distinction will be readdressed at the end of this section when we summarize all the observations. Figure 2 gives the magnetometer records and MSP $630.0 \mathrm{~nm}$ emissions observed at Gillam and Fort Smith. The Pi2 oscillations at these two stations resulting from passing the $\mathrm{Bx}$

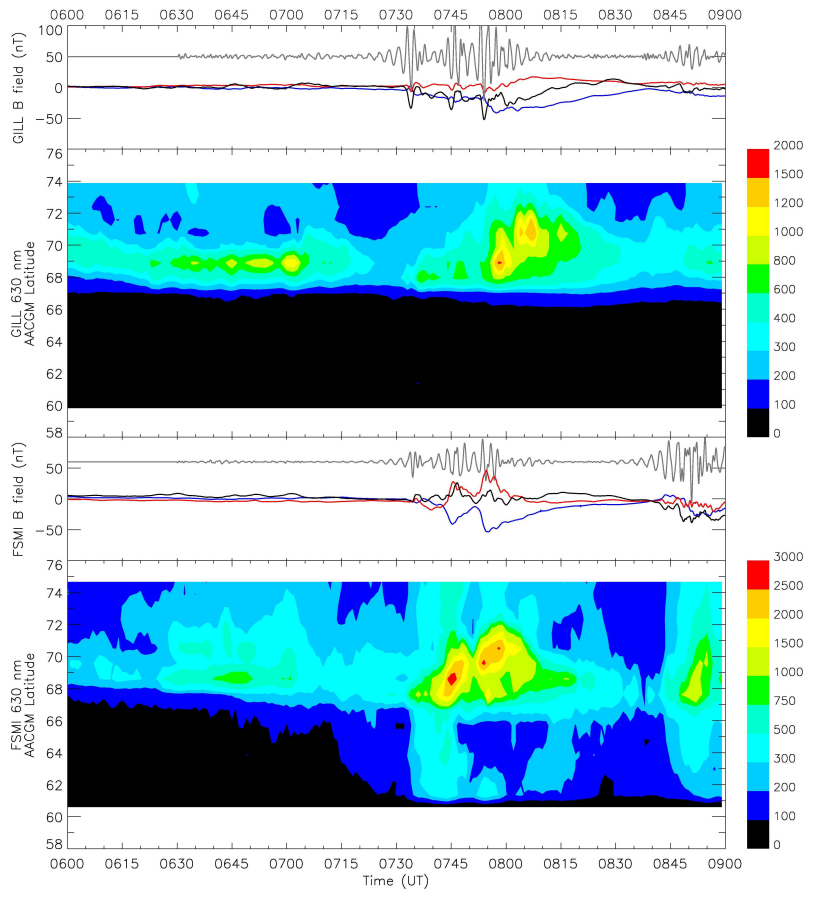

Fig. 2. Magnetic field data (panel 1 and 3) and MSP $630 \mathrm{~nm}$ emissions (panel 2 and 4) from 06:00-09:00 UT observed at Gillam and Fort Smith. In panel 1 and 3, the black, red and blue lines denote the X (magnetic north), Y (magnetic east), and Z (vertically downward) components of the magnetic field. Pi2 oscillations at both stations are also plotted in gray line on top of magnetometer traces with scale of $5 \mathrm{nT}$ per minor tick.

component through a bandpass filter for periods from 40 to $150 \mathrm{~s}$ are also shown. Negative X-component bay perturbations and associated $\mathrm{Pi} 2$ pulsations featuring three activations are clearly seen on the Gillam magnetometer. The magnetic perturbation was small at Fort Smith during the first pseudobreakup interval. However, for the second pseudobreakup and the substorm EP onset, at Fort Smith there were short-lived positive excursions of both the X- and Y components magnetic components, which is the signature of a westward traveling surge (WTS) passing over the station. In terms of the auroras, the optical emissions began to intensify from about 07:35 UT along both the Gillam and Fort Smith MSP lines. At 07:40 UT, a strong auroral intensification was detected by the Fort Smith MSP. The intensification structure was slightly slanted, showing an increase of latitude with time, which would imply a poleward motion of the auroral structure. East of Fort Smith, the Gillam MSP observations showed no strong intensification at that time but only a relatively weak enhancement starting at 07:43 UT. By $~ 07: 54$ UT, both the Gillam and Fort Smith MSP plots showed strong auroral brightenings which extended well beyond $71^{\circ}$ MLAT. It should be noted that, when the strong auroral breakup occurred, the intensification structure was seen best by the Fort Smith MSP at latitudes above $69^{\circ}$ MLAT, which seems to contradict the classical scenario that the 


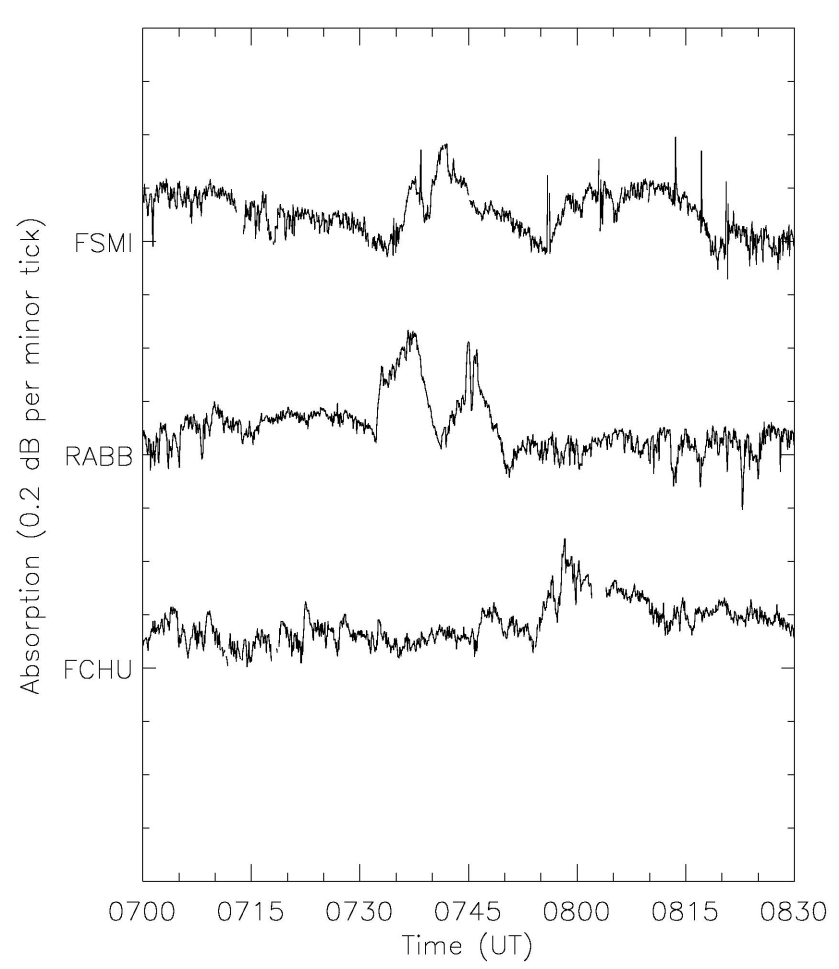

Fig. 3. Riometer observations from 07:00-08:30 UT at Fort Smith, Rabbit Lake, and Fort Churchill stations.

substorm-associated auroral brightening usually begins at the equatorward-most arc in the auroral oval (Akasofu, 1964). The Gillam MSP observations also showed that the intensification region was definitely poleward of $\sim 68^{\circ}$ MLAT, again at latitudes somewhat higher than the equatorward border of the auroral oval. However, we will argue that this behaviour is a local effect due to the one-dimensional nature of the MSP measurements. The initial auroral brightening at the very beginning of an EP onset appears to have occurred in the equatorward part of the auroral oval at a longitudinal position somewhere between Gillam and Fort Smith. The subsequent brightening would propagate both westward and eastward, as well as poleward. Therefore the auroral brightening observed on the MSP scan line would be located at latitudes greater than the initiation site latitude. As we will show later from the two-dimensional NASI observations, a significant auroral brightening was found at the southwestern edge $\left(\sim 67.5^{\circ}\right.$ MLAT) of the NASI FoV.

Starting at $\sim 08: 02$ UT, there is another auroral brightening, which can be seen from the Gillam MSP data, and the NASI observation shown later (see Panel 3 in Fig. 7). Also, the Eskimo Point magnetometer observations show a second $\mathrm{X}$-component magnetic bay which began at $\sim 08: 02 \mathrm{UT}$ and was even stronger than the $\sim 07: 52$ UT onset bay (see Fig. 2 in LJ04). Such a second-stage auroral brightening and its associated convection signature were investigated in LJ04, and were found to be consistent with the Stage-2 EP suggested by Erickson et al. (2000). This feature will not be studied again in this paper.
Figure 3 shows the riometer observations at several CANOPUS stations. At 07:32 UT, when the first Pi2 event and the auroral intensification began, there was a very steep rise in the $30 \mathrm{MHz}$ cosmic radio wave absorption. About 2 min later a rise in absorption was also seen at Fort Smith. The riometer data at Fort Churchill did not show any rise of absorption corresponding to the first pseudobreakup because the first auroral activation never reached this poleward latitude. A second rise of absorption was first seen at Fort Smith at $\sim 07: 39 \mathrm{UT}$, and subsequently at Rabbit Lake at $\sim 07: 42$ UT, and also at Fort Churchill (albeit a very small rise) at $\sim 07: 44$ UT. Starting at $\sim 07: 54$ UT, another large increase of the absorption, which accompanied the substorm EP, was seen almost simultaneously at Fort Churchill and Fort Smith. No noticeable propagation effect could be determined at that time. Thus, the riometer observations are consistent with the magnetic and optical auroral observations in that the riometers confirm the existence of three successive activations. Furthermore, the riometer observations provide important information about the origin and the subsequent propagation of the three activations.

\subsection{The NASI $630 \mathrm{~nm}$ observations}

The key observations for the event are the two-dimensional auroral emission images. The NASI data used in this paper are the raw data numbers after the flat-field calibration, which resolved the zenith angle dependence of the emission intensity. The flat-field calibration is usually accurate only at zenith angles less than $75^{\circ}$. Beyond that, the calibration tends to overamplify the emission intensity. However, to have a full view of the auroral region, especially because that in this event the initiation was close to Rabbit Lake, for which the red-line emission is at about $80^{\circ}$ zenith angle as seen from Rankin Inlet, we were forced to compromise and use an upper limit of $80^{\circ}$ zenith angle. One should keep in mind that the absolute emission intensities near the edge of the FoV are likely to be somewhat amplified. The assumed emission height was determined from a best-fit parallax technique based on the comparison between the NASI and Gillam MSP observations, which is in principle similar to the triangulation method for two MSPs developed by Jackel et al. (2003).

Figure 4 gives the combined NASI $630 \mathrm{~nm}$ image and the SuperDARN convection velocities obtained from the Saskatoon and Kapuskasing radars from 07:30 to 07:38 UT. The NASI $630 \mathrm{~nm}$ images are acquired once every $20 \mathrm{~s}$, so each 2min frame in the figure is an average of up to 6 such images. The convection velocity maps are based on the global potential mapping procedure of Ruohoniemi and Baker (1998). It should be noted that the SuperDARN convection velocities and the red-line emissions are both ionospheric $F$-region features, so combining them on one plot provides a reasonable picture of $F$-region ionospheric activity. The global ionospheric convection during the event sequence, and its association with the solar wind activation as well as its implication for the substorm evolution, were discussed in LJ04 and will not be repeated here. Instead, this paper will focus 
mainly on a detailed study of the optical auroral dynamics of the event.

Figure 4 shows that, for 07:30-07:32 UT, there was diffuse weak aurora in the eastern half of the FoV, extending longitudinally from 02:30 to 03:00 MLT, but there was almost no activity near midnight. There are several possible causes of that diffuse weak aurora. It could have been due to excitation of oxygen by secondary electrons which had energies of about $5-10 \mathrm{eV}$ and which resulted from proton precipitation. It is also possible that the diffuse aurora was caused by electron precipitation associated with electrons that had curvature-gradient drifted in the magnetotail from the midnight sector toward the morning sector, where there is evidence of a partial ring current. This emission region remained relatively unchanged in the eastward portion of the FoV during the subsequent more dynamic auroral activations which originated from the southwestern portion of the NASI FoV. It was in the latter region that the original patch subsequently brightened and spread eastward.

Clearly, by 07:32-07:34 UT, a midnight auroral patch had appeared at about $67-68^{\circ}$ MLAT and -36 to $-40^{\circ}$ MLON. The patch was just east of Rabbit Lake $\left(-42.48^{\circ}\right.$ MLON). This intensification occurred in conjunction with both the first Pi2 burst and the first cosmic radio absorption enhancement starting at 07:32 UT at Rabbit Lake. Stoker et al. (1996; 1997) found that cosmic radio waves of decameter wavelength appeared to be absorbed more strongly in regions adjacent to discrete auroral arcs. In this regard, we notice that there is a void in the radar echoes within and near the intensified patch. That void was most likely due to the increasing absorption. It is interesting to notice that the auroral evolution involved a series of discrete patches. While the initial patch brightened and broadened, another distinct patch appeared at $\sim-35^{\circ}$, east of the initial patch. By 07:3607:38 UT those two patches had almost merged together, while a third "detached" patch had appeared again at $\sim-32^{\circ}$ MLON.

Figure 5 shows the image from 07:40 to 07:48 UT, which is the interval of the second auroral intensification and the associated Pi2 burst. At 07:40-07:42 UT, the overall emission intensity was lower than in the previous frame at 07:3607:38 UT, but a new set of discrete patches had emerged in the longitudinal sector from local midnight to 01:00 MLT. Those patches were found to have an alignment approximately perpendicular to the flow direction, and thus roughly parallel to the electric field. Those discrete patches intensified considerably by 07:42-07:44 UT. During the next two frames, those patches not only significantly brightened but also broadened and tended to merge. On the west side of NASI image, the poleward border of the bright aurora region had slightly expanded to $\sim 70^{\circ}$ MLAT.

Figure 6 shows four images from 07:52 to 08:00 UT, which corresponds to the substorm EP interval. The auroral luminosity started to increase and expanded poleward following the onset at 07:52 UT. By 07:54-07:56 UT, significant auroral brightening and poleward expansion to $\sim 71.5^{\circ}$ MLAT had occurred. Embedded in the diffusive

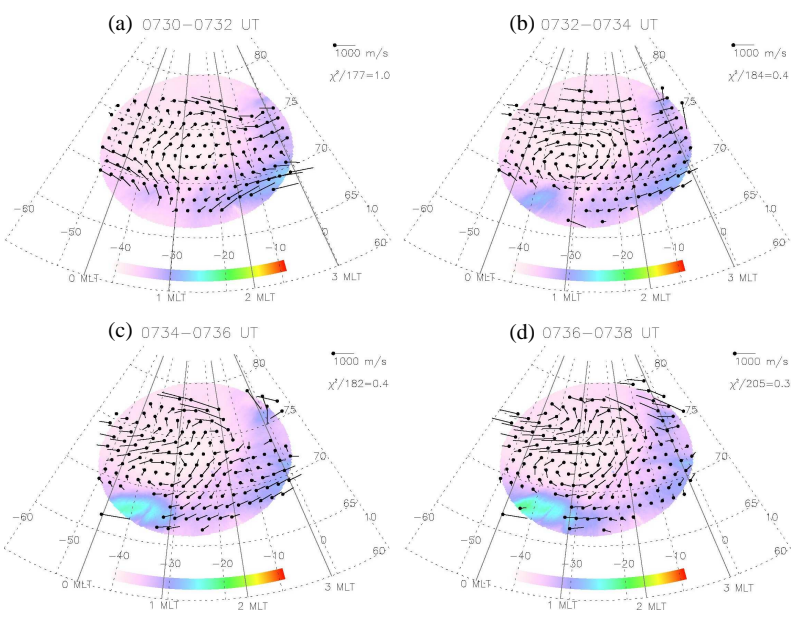

Fig. 4. Maps showing the NASI $630.0 \mathrm{~nm}$ emissions and the SuperDARN convection velocities (arrows) obtained from the FIT procedure (Ruohoniemi and Baker, 1998) during the intervals 07:3007:38 UT. The radar data is for a standard 2-min scan, while the 20 -s NASI data is averaged over that same 2-min interval. The chisquared value and the number of actual data points are labeled in the upper right corner of each frame.
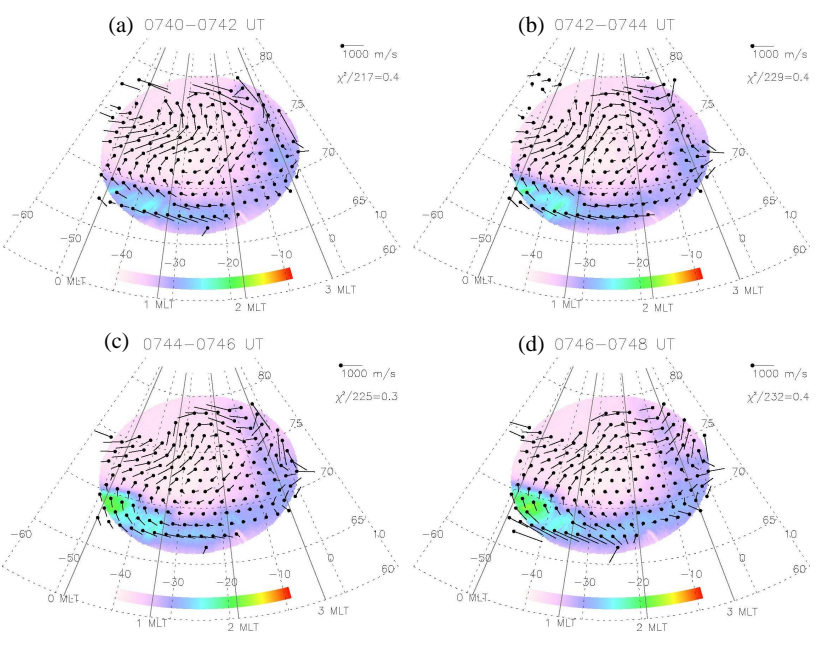

Fig. 5. Maps similar to Fig. 4, but for the period 07:40-07:48 UT.

bright auroras are two clear discrete patches separated by $\sim 9^{\circ}$ in MLON. Again we notice these two patches were aligned nearly perpendicular to the flow direction. By 07:5607:58 UT, both of these discrete patches had significantly broadened to bridge the gap between the two patches, but some fine structures seen as "split arcs" had developed. By 07:58-08:00 UT, the patch to the west had faded but the other continued to grow. An undulation in the auroral poleward border at $\sim 72^{\circ}$ MLAT can also be identified. In addition to the pronounced auroral brightening and poleward expansion, an overall eastward evolution of auroral brightening to $\sim 1.8$ MLT is also clear from the plot sequence.

The high temporal resolution (20 s) of the NASI observations enables a detailed investigation to be made on the initi- 

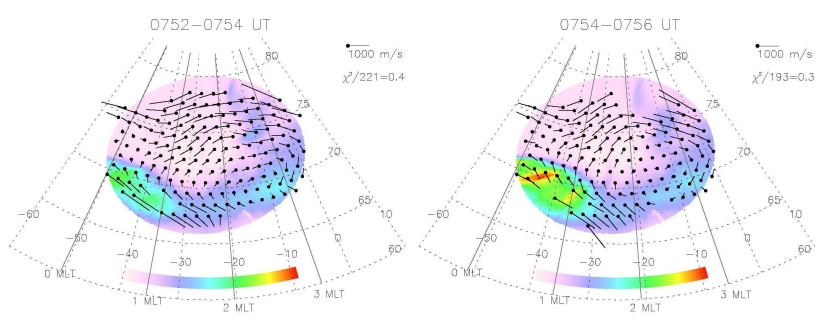

(c)
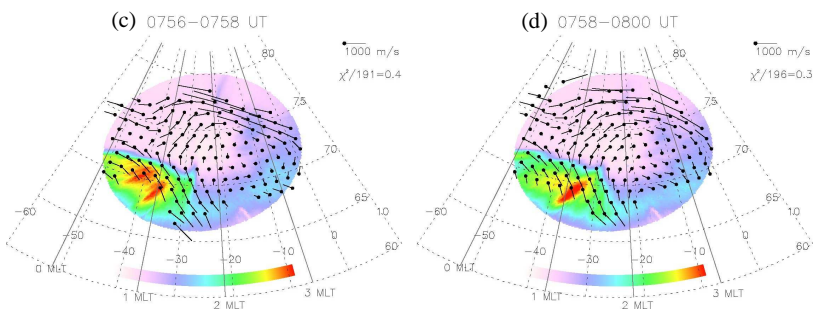

Fig. 6. Maps similar to Fig. 4, but for the period 07:52-08:00 UT.

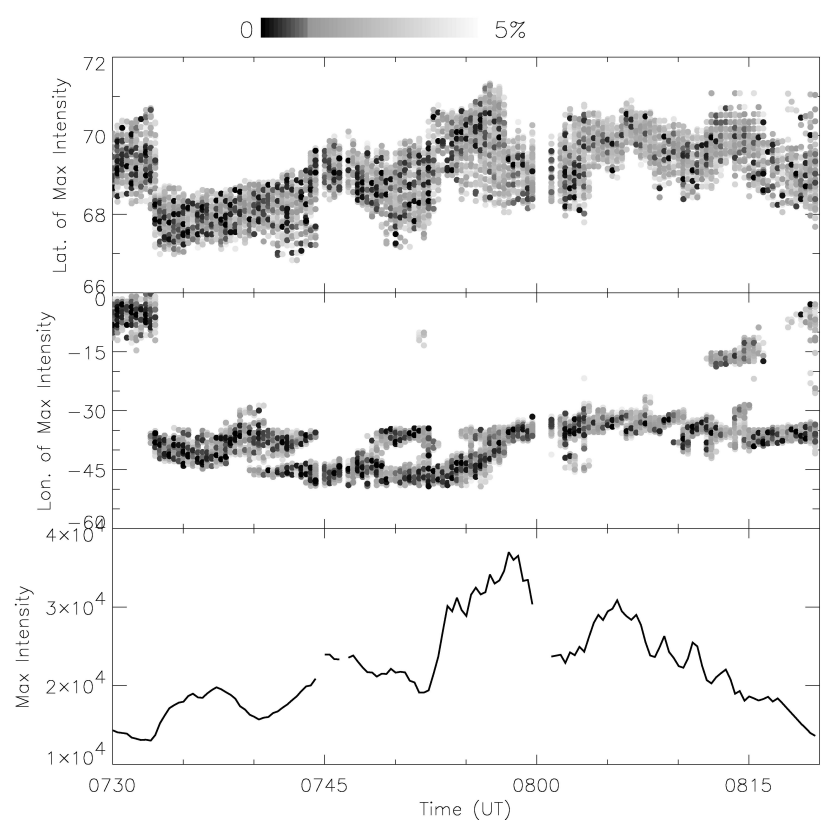

Fig. 7. The top two panels show the time plots of the latitude and longitude of the NORSTAR image pixels where the $630.0 \mathrm{~nm}$ intensity is within $5 \%$ of the maximum. The third panel shows the maximum intensity versus time.

ation and evolution of the auroral structures during each activation. The NASI image pixel locations of the band of maximum intensity were plotted as a function of time. The resulting plot, Fig. 7, shows the latitude/longitude band of maximum luminosity versus time, and the maximum intensity versus time, from top to bottom, respectively. The gray band indicates intensities within $5 \%$ of the maximum intensity. To reduce the error caused by the flat-field calibration for large zenith angle observations, we will use the radially-integrated emission intensity to investigate the azimuthal auroral structure. This intensity is determined by integrating the raw data number (after the flat-field calibration) between zenith an-

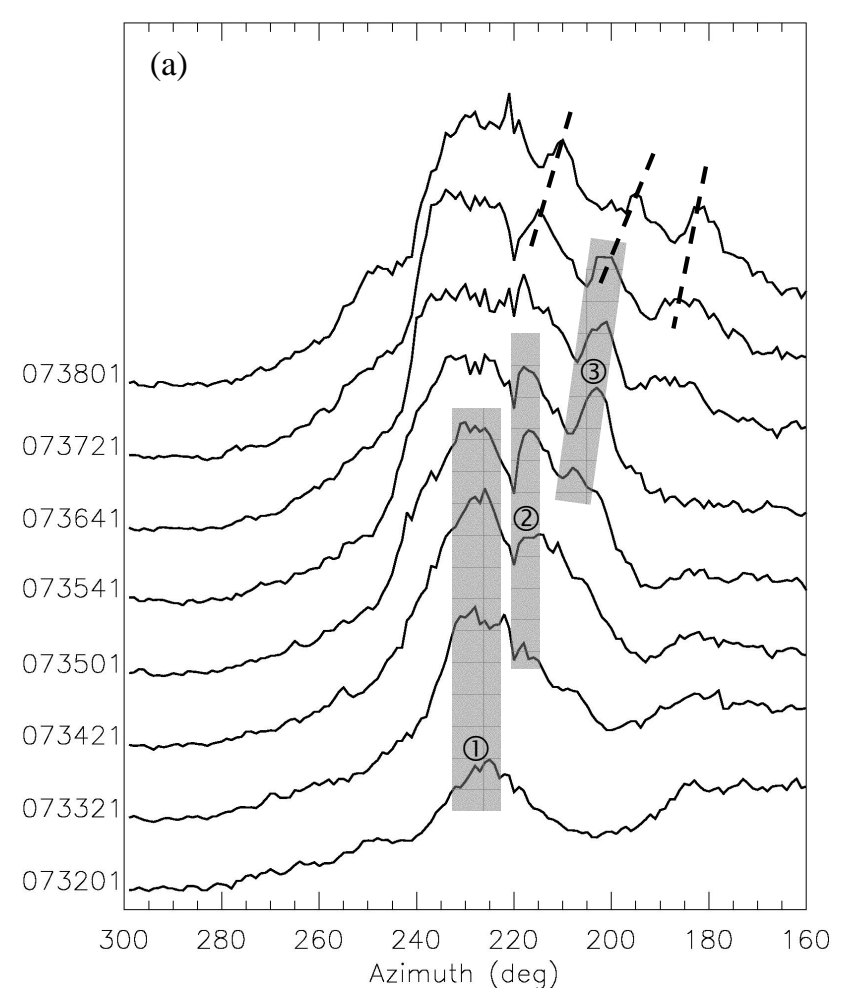

(b)

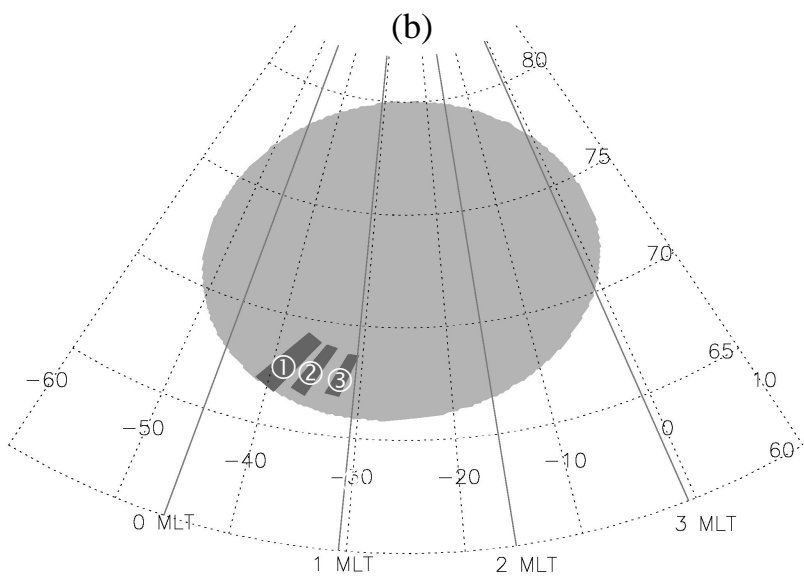

Fig. 8. (a) The radially-integrated $630 \mathrm{~nm}$ emission intensity versus azimuth angle observed by NASI during the first pseudobreakup interval. The observation time in UT is labeled on the left of each curve. Numbered gray bands indicate several intensified patches. (b) The approximate geomagnetic position of the discrete patches (dark boxes). The gray circle indicates the FoV of the NASI at Rankin Inlet.

gles $58^{\circ}$ and $78^{\circ}$, which fully covers the region of bright aurora, and within every $1^{\circ}$-wide NASI azimuthal channel (the NASI azimuth is 0 for geographical north and increases in the clockwise sense). The results are shown in Figs. 8-10.

As noted earlier, there were diffuse weak aurora emissions present in the eastern part of the FoV before 07:32 UT. This is seen in Fig. 7 as the region of diffuse intensity north of $68.5^{\circ}$ MLAT and east of $-15^{\circ}$ MLON just before 07:32 UT. However, the growth of the first Pi2-associated patch of aurora 
began at about 07:32 UT, and the region of maximum intensity underwent a dramatic shift to the southwest part of the NASI FoV at about $-40^{\circ}$ MLON, as shown in Fig. 7. This first pseudobreakup was rather stable in latitude (67-68 MLAT) after its initiation and showed no significant poleward propagation. Figure 8a gives the radially-integrated emission intensity versus the NASI azimuth angle during the first Pi2 burst and auroral intensification interval. In Fig. 8a, the first patch was located at $\sim 225^{\circ}$ azimuth at 07:32:01 UT. By 07:33:21 UT, the patch had expanded both westward and eastward, while a small "bump" appeared at $\sim 217^{\circ} \mathrm{az}-$ imuth. This small "bump" grew in magnitude and also broadened as it evolved into another intensified patch seen clearly from 07:34:21 UT to 07:35:41 UT. Another small "bump" at $\sim 207^{\circ}$ azimuth in turn appeared at 07:35:01 and developed into a third intensified patch seen clearly from 07:35:41 UT to $07: 37: 21$ UT. The third patch showed a slope toward decreasing azimuth with time, which implied an eastward motion of the patch. In Fig. $8 \mathrm{~b}$ we show the approximate geomagnetic positions of the above three successive discrete patches, based on Fig. 8a. The expansion of the originally azimuthally separated patches 1 and 2 gradually bridged the gap between them. By 07:36:41 UT those two patches had merged and formed an overall enhancement of luminosity over a broad region, though much fine structure still existed. At the same time a new patch on the east, initially weak and diffuse, began to develop at $\sim 190^{\circ}$ azimuth. Afterwards, several wave-like patches were discernible but all clearly showed pronounced eastward motion (indicated by dashed lines). A cross-correlation analysis among several successive frames after 07:37:21 UT revealed that the eastward speeds of those patches, assuming them to have been located at $68^{\circ}$ MLAT and $215 \mathrm{~km}$ height, are $980 \pm 150 \mathrm{~m} / \mathrm{s}$.

The second epoch of auroral intensification started at $\sim 07: 40$ UT, as seen from the second rise of maximum emission intensity shown in the bottom panel of Fig. 7. At that time, a new high intensity structure emerged at about $-45^{\circ}$ MLON and $67-68^{\circ}$ MLAT, near the southwestern edge of the NASI FoV. During the second auroral activation interval, the intensification structure first moved poleward up to $\sim 69.5^{\circ}$ MLAT until 07:45 UT, but then retreated equatorward to $\sim 67.5^{\circ}$ MLAT. In Fig. 9, some structures persisted as remnants of the first pseudobreakup activity. However, a new patch at $\sim 250^{\circ}$ azimuth (the actual emergence time of this patch was $\sim 07: 39$ UT) led a new series of discrete intensified patches and thus a second epoch of auroral activation. Another patch at $\sim 237^{\circ}$ azimuth started to form at 07:40:21 UT and showed a slight eastward motion afterwards. A third patch at $\sim 225^{\circ}$ azimuth appeared at 07:42:21 UT. The approximate geomagnetic positions of the three discrete patches are plotted in Fig. 9b. It should be noted that, because the first midnight patch appeared at near the southwest edge of the NASI FoV, there is a strong possibility that the actual initiation site was further west and/or south of the NASI FoV. We notice that patch 3 disappeared momentarily at 07:42:21 UT, and reappeared at 07:42:42 UT, at which time patch 2 disappeared. After-

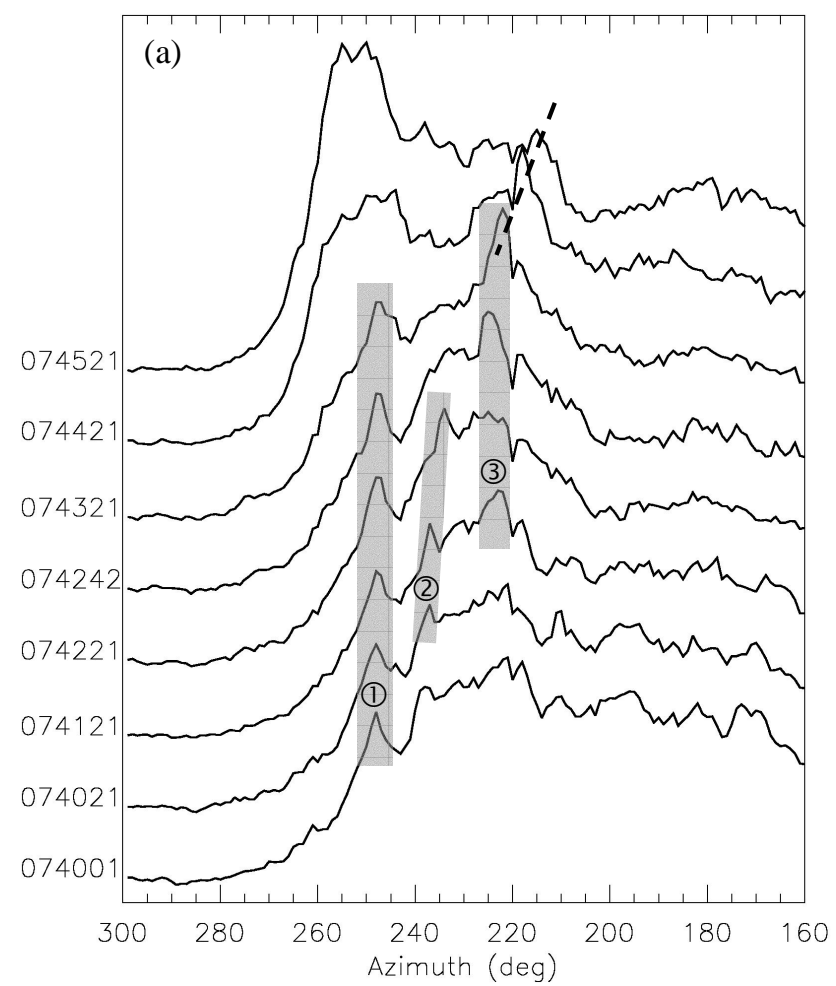

(b)

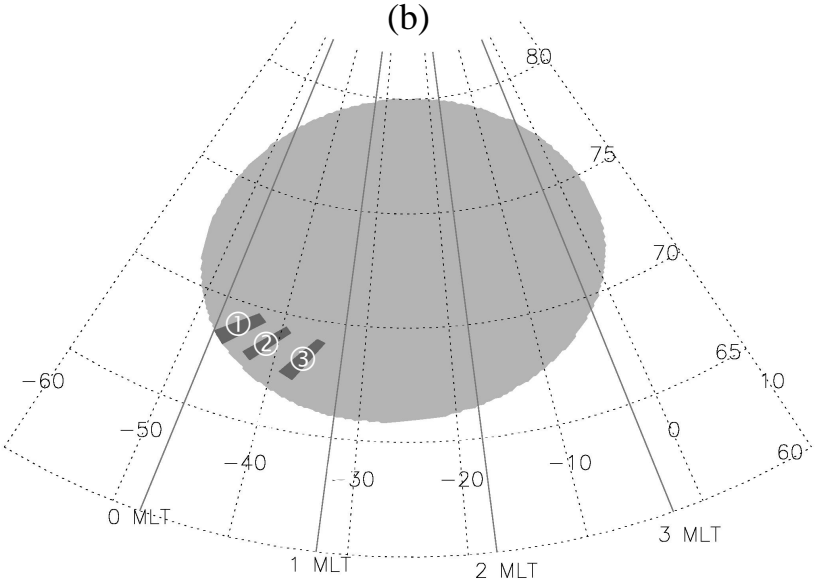

Fig. 9. Same as Fig. 8, but for the second pseudobreakup interval.

ward patch 3 showed a clear eastward motion with velocity of $865 \pm 50 \mathrm{~m} / \mathrm{s}$, and original patch 1 significantly intensified and broadened at 07:44:21 UT and 07:45:21 UT. An overall enhancement of auroral luminosity over a broad region between patches 1 and 3 was seen.

The interval of special interest is from 07:52 to 08:00 UT, during which the auroral emission enhancement was much stronger than the previous two activations. Notice in Fig. 7 that, at the start of this activation, the brightening pixels within the NASI FoV were initially found at as far equatorward as $\sim 67.5^{\circ}$ MLAT and as far east as $-50^{\circ}$ MLON. It should be noted that, since the brightening was seen to the very southwestern edge of the NASI FoV, the actual origin of the activation might have been even further 


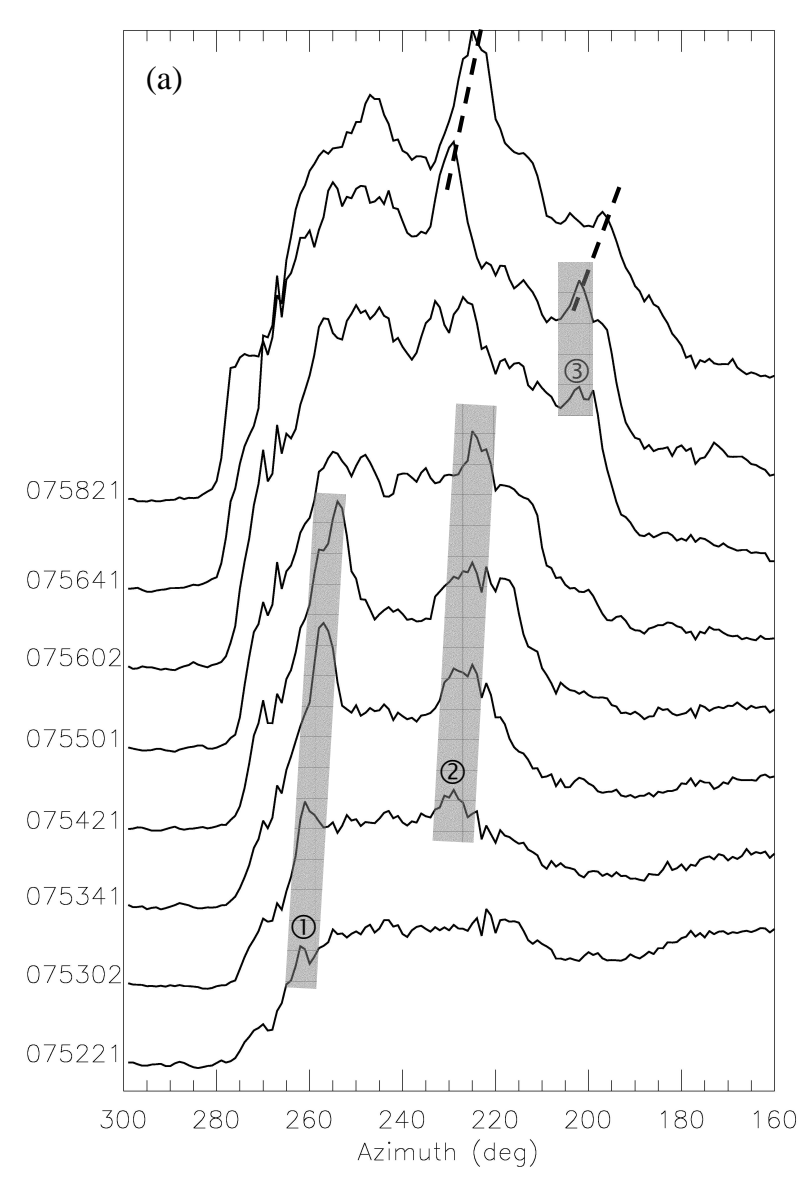

(b)

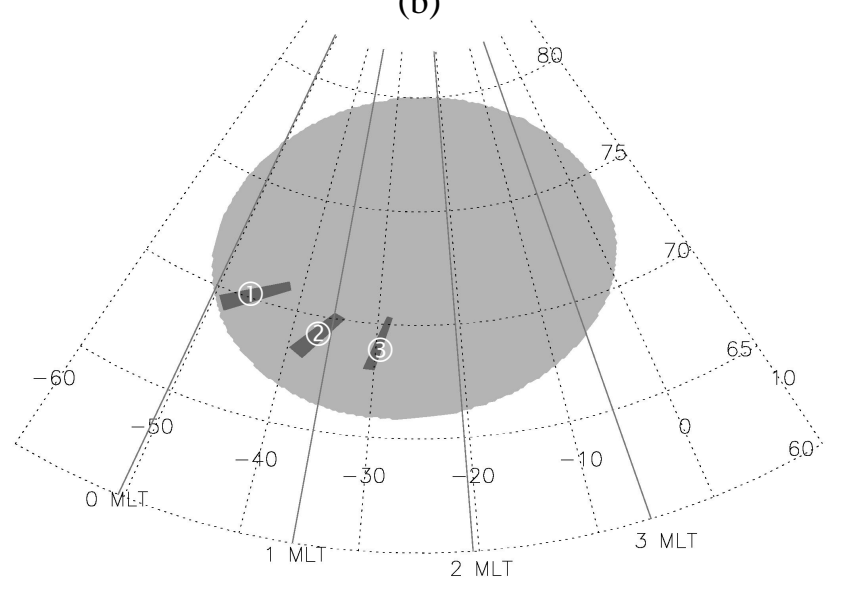

Fig. 10. Same as Fig. 8, but for the substorm EP interval.

south and/or west. After its initiation the bright regions moved significantly poleward to $>71^{\circ}$ MLAT and eastward to $\sim-35^{\circ}$ MLON. A north-east propagation of the auroral brightening is thus easily identified. After 07:58 UT the activation decayed, and the regions of maximum intensity retreated in latitude to $68.5-69^{\circ}$ MLAT but remained relatively stable in longitude.

Figure 10a shows that the very first hint of the appearance of the westernmost patch was at $\sim 260^{\circ}$ at 07:52:21 UT. By 07:53:02 UT the initial patch had grown and another patch had appeared at $\sim 230^{\circ}$ azimuth. Those two patches strongly intensified and broadened up to 07:54:21 UT, and showed a slight eastward trend in their motion. As in the two previous activations, the two separated patches merged. The gap between them became filled by an auroral luminosity enhancement until there was virtually no gap at 07:55:01 UT. However, a considerable amount of fine structure in the intensity remained. A new weaker patch at $\sim 200^{\circ}$ azimuth appeared at 07:56:02 UT. After 07:56:41 UT, the $\sim 230^{\circ}$ patch intensity increased significantly, and there was an obvious eastward motion of all patches. From a cross-correlation analysis the eastward velocity was estimated to be $690 \pm 80 \mathrm{~m} / \mathrm{s}$ at $\sim 68^{\circ}$ MLAT.

In summary, the NASI observations with 20-s resolution behaved such that, during each auroral activation interval, several discrete intensified auroral patches could be identified. These patches have exactly the same signature as the azimuthally-spaced auroral forms (AAFs) reported by Elphinstone et al. (1995). The patches appeared in a sequence such that each new patch formed a little to the east of the previous one. In agreement with the Elphinstone et al. (1995) AAF observations, the patches tended to propagate eastward in the postmidnight sector. After their initial appearance, the patches usually intensified and also expanded. The gaps between the patches were gradually filled with diffuse auroral luminosity, although discrete auroral structures persisted and usually showed an obvious eastward motion $(600-1100 \mathrm{~m} / \mathrm{s})$ after the diffuse auroral luminosity enhancement. Since such intensified optical auroral patches was presumably associated with small-scale upward FAC structures, the eastward motion of those patches is consistent with the feature, and likely to be the optical counterpart, of the azimuthally propagating vortical current (APVC) associated with upward FACs in the postmidnight sector and usually observed after substorm EP onset (Wild and Yeoman, 2000).

Figures $8 \mathrm{~b}$ to $10 \mathrm{~b}$ reveal another interesting feature, namely that the azimuthal separation between the patches tended to increase during the event sequence. For example, at the start of the first pseudobreakup interval, the first two patches were separated by $2-3^{\circ}$ MLON, while during the second pseudobreakup, the separation between adjacent patches was $4-5^{\circ}$ MLON. By the time of the Stage- 1 substorm EP, the separation had increased to $8-9^{\circ}$ MLON.

\subsection{Observations at the geosynchronous orbit}

Two of the GOES geosynchronous satellites were so located as to provide useful information for the event. Unfortunately, they were not at positions that map to the radar and optical observation areas. GOES-10 was located to the west of our ground-observation area, and GOES- 8 to the east. The ionospheric footprints of GOES-8 and GOES-10 were calculated from the T89c model (Tsyganenko, 1989) with $\mathrm{Kp}=1$, and were plotted as asterisks in Fig. 1. Figure 11 gives the magnetic fields measured by the two satellites from 07:00 to 09:00 UT. The GOES magnetic fields are converted to the VDH coordinate system, in which $\mathrm{H}$ is antiparallel to 
the dipole axis, $\mathrm{V}$ is radially outwards and is parallel to the magnetic equator, and $\mathrm{D}$ completes the right-hand orthogonal system and is positive eastward. The magnetic elevation angle $\theta_{B}$, which is defined by the equation,

$\theta_{B}=\arctan \left(-B_{H} / B_{V}\right)$,

is used to identify the dipolarization. On GOES- 8 the $\theta_{B}$ value increases from $49.6^{\circ}$ to $52^{\circ}$ during the interval $07: 30$ 08:15 UT. This change is much smaller than that seen in a typical substorm dipolarization event $\left(\sim 10^{\circ}\right.$ change within $10 \mathrm{~min}$ was reported by Liou et al., 2002) but it nevertheless indicated a slight magnetic dipolarization at geosynchronous orbit. Considering that the substorm event studied in this paper is a minor and localized, and that, as shown by the NASI data, the auroral brightening never reached 03:00 MLT during the whole event, the small magnitude of the dipolarization observed on GOES-8 is reasonable. The GOES- 8 data reveals that the dipolarization progressed in a multi-step way. The start times of each stepwise increase (shown by dotted lines in the bottom panel of Fig. 11) were found to be in accord with the start times of the three Pi2s and the associated auroral activations. On the other hand, on GOES-10 the $\theta_{B}$ values were decreasing, so no magnetic dipolarization effect was seen. However, there were some small wave-like perturbations of magnetic fields with periods of $\sim 5 \mathrm{~min}$ from 07:32 to 08:05 UT (best seen in the GOES-10 H component). These indicate the existence of ULF Pc5 waves at geosynchronous orbit in the premidnight sector during the event interval. Magnetic perturbations of similar periods were also frequently observed at the CRESS satellite during the substorm EP (Erickson et al., 2000). One possible cause could be the excitation of ULF Pc5 waves by drifting energetic particle fluxes via the drift and drift-bounce resonances (Southwood and Kivelson, 1982; Yeoman and Wright, 2001). The source of the westward-drifting energized protons is likely to have been the substorm-activated plasma sheet in the midnight sector. Energetic ions which were accelerated at the inner edge of the plasma sheet could have curvature-gradient drifted westward and produced the Pc5 pulsations on the GOES-10 via the drift resonance interaction.

On the basis of the geosynchronous measurements and the convection, optical, magnetometer and riometer observations, some final remarks on the initiation and the spatial extent of the three auroral intensifications may be made. The site of the first activation at 07:32 UT was unambiguously determined from the NASI observations to be at $\sim-39^{\circ} \mathrm{MLON}$, as seen from Fig. $4 \mathrm{~b}$. At the same time, there was an abrupt rise in the $30 \mathrm{MHz}$ cosmic radio wave absorption at Rabbit Lake (see Fig. 3), just west of the initiation site. However, the original sites for the second and third auroral intensifications are not as clear. The Rankin Inlet NASI observations show that, for those two activations, the initial intensification occurred at the western edge of the FoV at midnight, indicating that the origin of that activation likely was located west of the NASI FoV, in the premidnight sector. For the second auroral activation, the MSP observations at Fort Smith showed much stronger emissions than

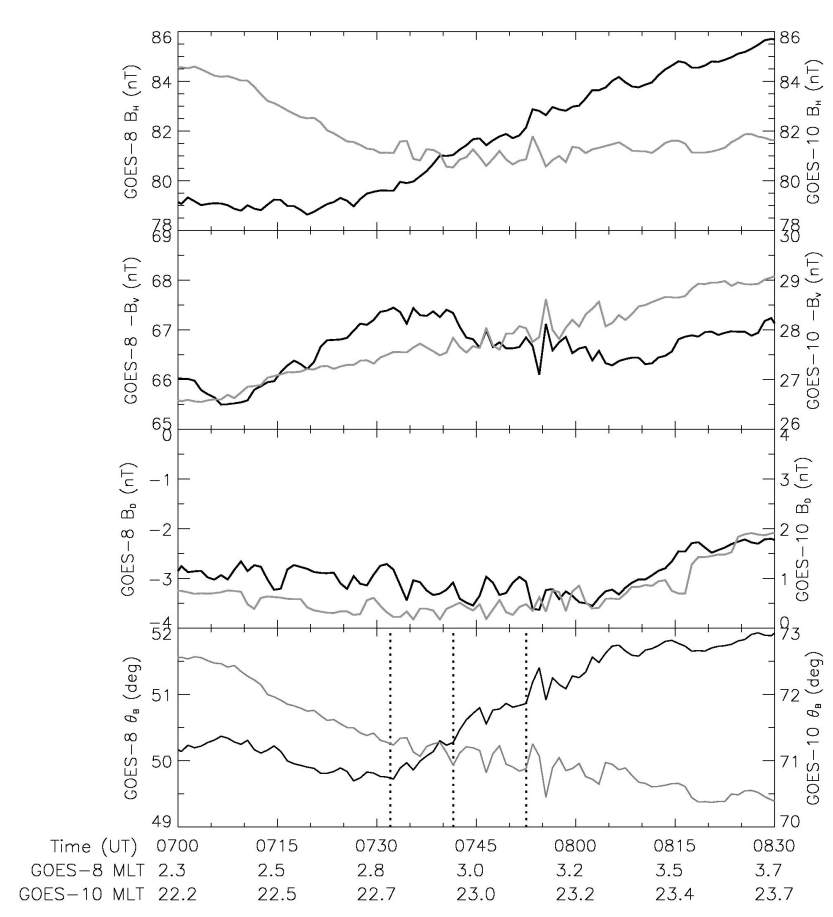

Fig. 11. Magnetic fields observed by GOES-8 (black line, left coordinate axis) and GOES-10 (gray line, right coordinate axis). The first, second, and third panels show the $B_{H},-B_{V}$, and $B_{D}$ components, respectively. The fourth panel gives the magnetic elevation angle defined by Eq. (1). The MLT of the ionospheric footprint of the satellites, labeled at the bottom of the plot is calculated from the T89c model (Tsyganenko, 1989) with $K_{p}=1$.

the Gillam MSP results. The riometer data also showed that the increase in absorption occurred first at Fort Smith, subsequently at Rabbit Lake and then at Fort Churchill, each separated by $2-3 \mathrm{~min}$. Also, scrutiny of Fig. 2 reveals that the second Pi2 burst appeared first at Fort Smith and several minutes later at Gillam. The third activation differs from the previous two in several aspects. First, the magnitude of the magnetic disturbances (see Fig. 2 in LJ04), and the intensity of the auroral emissions (see panel 3 in Fig. 7) were much stronger in the third activation. Secondly, only the third activation was associated with a significant poleward expansion $\left(>70^{\circ}\right.$ MLAT) of the bright aurora, which can be seen clearly from Fig. 6 as well as the top panel of Fig. 7. Also, the riometer observations show that at Fort Churchill significant absorption enhancement occurred only during the third activation interval when the auroral expansion already had passed the station latitude. Therefore we have classified the third activation as a substorm EP, distinct from the previous two "pseudobreakups". The auroral intensifications observed from MSPs at Fort Smith and Gillam, as well as the absorption enhancement seen from riometers at Fort Churchill and Fort Smith, all occurred nearly simultaneously at $\sim 07: 54$ UT for the third activation.

We were unable to find other observation sets that could have been used to determine the exact initiation sites for the 


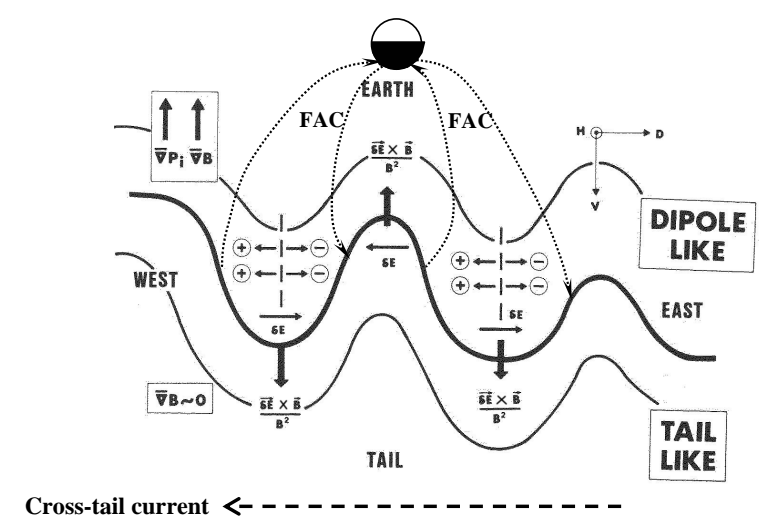

Fig. 12. Sketch of the drift wave instability at the neargeosynchronous plasma sheet. See the text for explanations.

second and the third activations. However, as mentioned previously, the short-lived positive excursions of the $\mathrm{X}$ and $\mathrm{Y}$ magnetic components at Fort Smith at the start of the second pseudobreakup and the substorm EP are indicative of a passing WTS. Therefore we may infer that the initiation sites of the second and third activations were east of Fort Smith. For the second activation, the initiation site may have located close to Fort Smith so that the auroral, magnetic, and riometer signatures were first seen there and later expanded to "Manitoba line" stations. The initiation of the third activation (substorm EP), as we argued before, may have located somewhere longitudinally about midway between Gillam and Fort Smith, so that the required time for the eastward propagation to "Manitoba line" stations and the westward propagation to Fort Smith would be roughly the same. The geosynchronous GOES-10 data clearly shows that the western limit of all three activations never reached $\sim 23: 00$ MLT because no dipolarization effect was ever seen at GOES-10, but for each activation there was a small but clearly identifiable dipolarization effect seen on GOES-8 at 03:00 MLT. Furthermore, seen from the global SuperDARN convection observations presented in Fig. 3 in LJ04, the ionospheric convection in the postmidnight sector observed by the Saskatoon-Kapuskasing SuperDARN radar pair underwent dramatic changes during the whole event, but the premidnight convection observed by the Prince George-Kodiak radar pair was always small in magnitude and showed only slight changes in the pattern.

Considering all the facts above, the whole event is fundamentally different from "traditional" substorms which have an initiation site in the premidnight sector and normally show a well-defined westward propagation effect. In our event, the first activation occurred at $\sim 0.4$ MLT. The initiation sites of the second and third activations might have been located longitudinally a few tens of minutes prior to midnight, but they underwent quite asymmetric longitudinal expansions subsequently. The eastward expansion was prevalent and was detected in the postmidnight sector by the Rankin Inlet NASI, the CANOPUS magnetometers and the MSPs in that sector.

\section{Discussion}

A small substorm event has been described in detail, using optical, magnetic and radar observations. In this section we will try to interpret the observed auroral intensifications in terms of successive "drift" waves in the NGOPS and the DAB instability. The DAB instability has long been considered to be one of the principal candidates for triggering the near-geosynchronous onset of substorms. In particular, the CRESS satellite observations (Maynard et al., 1996; Erickson et al., 2000) provided convincing evidence relating the DAB instability at NGOPS to the substorm EP onset process.

The drift ballooning instability in its simplest form is a magnetospheric interchange instability along the boundary of two distinct regions (Southwood and Kivelson, 1987). A simplified sketch of the instability is shown in Fig. 12. The gradients of the pressure and magnetic field both point earthward between the boundary of the dipole-like region and the tail-like region. Assume that there is an initial density perturbation moving in the azimuthal direction. Energetic ions and electrons will undergo westward and eastward drifts, respectively. Positive and negative charges accumulate at the edge of the propagating perturbation, producing polarization electric field $\delta \mathbf{E}$ and generating FACs. The resulting $\delta \mathbf{E} \times \mathbf{B}$ force tends to enhance the amplitude of the initial perturbation so that the instability grows. The polarization electric fields that develop in these waves can grow to such a size that, in a specific half-cycle of the wave, the eastward polarization electric field can reach a sufficient magnitude to overcome the normal westward dawn-to-dusk electric field and thus produce a net eastward electric field. In this half cycle, $\mathbf{J} \cdot \mathbf{E}<0$ so this region acts as a "generator". Within that half-cycle the drift wave couples to the Alfvén ballooning mode and plasma kinetic energy is converted into electromagnetic energy which flows toward the ionosphere via Alfvén waves. Such a specific half-cycle of the drift wave was called a "trigger wave" by Erickson et al. (2000). When, during such eastward polarization electric field excursions, the energy is released from the plasma at a rate faster than the plasma is energized by the background convection, the cross-tail current is reduced, and magnetic field dipolarization begins. The eastward electric field also leads to a tailward expansion of the "trigger waves" which maps to the ionosphere as a poleward expansion of the auroral intensification.

The evolution of azimuthally-spaced intensified patches during each auroral activation, as shown in Figs. 8-10, provides evidence for the existence of such a drift wave structure in the NGOPS. Drift waves in a plasma with nonuniform pressure gradients usually exist in a form of partial standing wave, namely, a near-stationary standing wave within the region of strong pressure gradient, and gradual outward propagation and attenuation away from the region in both directions (e.g. Edwards and Rusbridge, 1982). If there exists a compression of plasma in the midnight sector, the noncollinearity of the pressure gradient and the field line curvature vector may facilitate the instability growth (Ivanov et al., 1992). The resulting wave vector of the DAB mode is 
preferentially westward in the premidnight sector and eastward in the postmidnight sector, but the tail conditions in these two sectors might differ in favoring the instability growth. In this particular event on 9 October 2000, we speculate that the instability was somewhat quenched somewhat in the premidnight sector since no subsequent magnetic dipolarization feature was seen there. On the other hand, a drift wave structure may have existed prior to the first pseudobreakup and extended into the postmidnight sector (see Fig. 13a), where the tail conditions favored an explosive growth of the instability. However, such waves usually suffered increasing attenuation with longitudinal distance and thus span only a few wavelengths in azimuth (Roux et al., 1991). With the growth of the instability, the wave packet in the midnight sector would first reach the "trigger wave" threshold (Fig. 13b), leading to the coupling of energy into the ionosphere and the formation of the initial auroral patch in the midnight sector. Away from the midnight sector, the drift waves might also grow to such a size that they become "trigger waves" some time later (Figs. 13c,d). Finally, beyond some azimuthal limit, the instability would be extinguished by damping. According to this scenario, discrete auroral patches would be expected to appear successively from near-midnight toward the morning sector, showing an eastward progression. The azimuthally-spaced auroral structures observed by NASI were the ionospheric manifestations of such "trigger waves" and the associated energy transport processes in the NGOPS.

When energy is released from the NGOPS plasma faster than the background convection energizes it, the crosstail drift current is disrupted, and magnetic dipolarization begins. The current disruption/dipolarization rapidly expand azimuthally (Lopez and Lui, 1990), spanning several wavelengths in azimuth as compared to the initial "trigger wave". This dipolarization process might have several consequences. First, the particle injection toward the inner edge of plasma sheet associated with the dipolarization may lead to enhanced electron precipitation via loss-cone scattering within the longitudinal extent of the dipolarization region, which explains the overall expansion and diffusive enhancement of the auroral luminosity after several intensifications of initially discrete and narrow patches. Second, the dipolarization may generate an earthward electric field in the central plasma sheet via a non-MHD "field-line slippage" process (Lui and Kamide, 2003). This earthward electric field would lead to an eastward convective motion of the plasma. From the convection maps Figs. 4-6 it can be seen that, though there were sometimes unfortunately voids in the radar coverage inside the regions of intensified aurora, the overall convection pattern had a marked eastward component during each activation. The drift wave structure would be imbedded in such eastward-convecting plasma. This explains why, as seen in Figs. 8-10, the discrete patches during each activation showed pronounced eastward motion after a diffuse enhancement of auroral emissions had taken place.

As mentioned earlier, the "trigger wave" during its eastward electric excursion produces Poynting flux which is car-

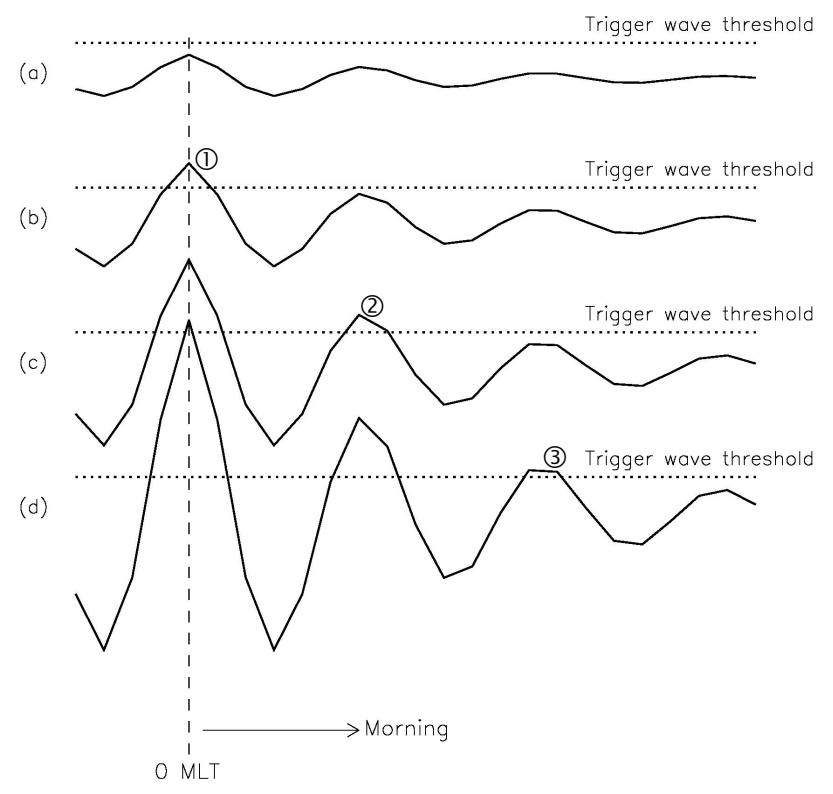

Fig. 13. A schematic diagram explaining the successive appearance of discrete auroral patches, which correspond to a series of "trigger waves" in the NGOPS.

ried toward the ionosphere by Alfvén waves. The Alfvén waves incident upon the ionosphere are partially reflected because of the impedance mismatch between the ionosphere and magnetosphere, effectively causing a secondary Alfvén wave to be launched from the ionosphere due to the disturbance of the ionospheric conductivities and electric fields. Such reflected secondary Alfvén waves carry return power from the ionosphere to the magnetosphere. These bouncing Alfvén waves establish the high-latitude Pi2 magnetic pulsations (Olson, 1999). However, the electric field oscillations within the drift waves may not be completely in phase with these bouncing Alfvén waves (in phase means that there would only be an incident wave into the ionosphere during a half cycle with eastward electric field excursion and only a reflected Alfvén wave out of the ionosphere during the westward electric field excursion). In the actual situation, interference between the incident and the reflected Alfvén waves may occur (Maynard et al., 1996). Such interference may modify the waveform of the initial "trigger wave" and thus cause fine structure in the auroral patch. Maynard et al. (1996) reported that, in one of their events, they found that a substorm expansion was already in progress when wave power returning from the ionosphere was observed at the CRESS satellite. However, the reflected Alfvén waves were out of phase with the magnetospheric electric field oscillation, with the result that the substorm electrojet turned off momentarily until the wave power and the electric field oscillations retuned to the in-phase condition. Figure 9 shows that, during the second auroral activation interval, patch 3 $\left(\sim 225^{\circ}\right)$ temporarily faded at 07:42:01 UT but was reactivated at 07:42:42 UT, while at the same time the original patch 2 totally disappeared. We believe such sequences are 
Table 2. Time interval and longitudinal distance of discrete auroral patches and the inferred phase velocity at geosynchronous orbit.

\begin{tabular}{lcccc}
\hline Activation & & $\begin{array}{c}\text { Time } \\
\text { interval }(\mathrm{s})\end{array}$ & $\begin{array}{c}\text { Longitudinal } \\
\text { distance }(\mathrm{deg})\end{array}$ & $\begin{array}{c}\text { Inferred phase } \\
\text { velocity a } L=6.7(\mathrm{~km} / \mathrm{s})\end{array}$ \\
\hline \multirow{2}{*}{ The first Pseudobreakup } & Patch $1->2$ & 100 & 2.5 & 19 \\
& Patch $2->3$ & 100 & 3.5 & 26 \\
The second Pseudobreakup & Patch $1->2$ & 80 & 4 & 37 \\
& Patch 2->3 & 60 & 5 & 62 \\
Substorm EP & Patch 1->2 & 40 & 9 & 167 \\
& Patch 2->3 & 140 & 8 & 43 \\
\hline
\end{tabular}

similar to the observations of Maynard et al. (1996) and have the same physical explanation, namely unfavorable (destructive) interference between the returning Alfvén waves and the "trigger waves" leading to quenching of the latter waves. When the energy contained in the drift wave at NGOPS is totally dissipated via the magnetosphere-ionosphere coupling, the DAB instability and thus the auroral activation diminish until the next epoch of disturbances at NGOPS lead to a new series of "trigger waves" and new auroral activations. The DAB instability was most well-developed during the third activation (substorm EP interval), in which the "trigger waves" had expanded substantially tailward, as shown by the poleward extension to $\sim 71^{\circ}$ MLAT of the discrete auroral patch seen in Fig. 6.

The time interval between successive appearances of discrete patches and their azimuthal distances in all three activations are listed in Table 2. To identify the time intervals, we used the whole sequence of NASI images separated successively by $20 \mathrm{~s}$. Within a given activation period, the emergence time of each discrete patch is defined as the time when the peak intensity of the growing patch exceeded the background value (prior to the existence of this patch) by $15 \%$. The longitudinal separations between successive patches are compatible with the Elphinstone et al. (1995) results that the mode number of the AAFs ranged between 30 to 135 , corresponding to an azimuthal wavelength of $2.7-12^{\circ}$. The inferred "apparent" phase velocities of these wave-like patches mapped to geosynchronous orbit $(L=6.7)$ are also given in Table 2. It is important to note that the actual form of the DAB wave is usually extremely complicated, and the apparent phase velocities of the discrete optical patches, considered as the ionospheric signatures of "trigger waves" in the NGOPS, do not purely represent the drift wave phase speed but also depend upon the instability growth rate as well as the azimuthal attenuation factor. For example, during the third activation (the substorm EP interval, see Fig. 10), patch 3 lagged patch 2 by a relatively long time $(\sim 2.5 \mathrm{~min})$. This is expected because patch 3 was located considerably eastward of the original origin of the disturbance (presumably near midnight) so that strong damping had significantly delayed the time at which the DAB amplitude was able to reach the "trigger wave" threshold. Nevertheless, a general trend of increasing drift wave phase speed, which in turn implied an enhancement of particle energy involved, can still be inferred from Table 2. By using the observed WTS expansion speed and simple linear DAB theory, Roux et al. (1991) estimated the energy of the ions involved to be $\sim 40 \mathrm{keV}$, for which the curvature-gradient drift velocity is about $100 \mathrm{~km} / \mathrm{s}$ at geosynchronous orbit. Since in our event the substorm development evolved in a multi-step fashion and there were successive dipolarizations of the NGOPS magnetic field after 07:32 UT, as inferred from the GOES- 8 observations in Fig. 11, the particles became more and more energized in the NGOPS to a few tens of keV. The increase in particle energy, and also in the associated drift wave phase speed, naturally led to an increase in the wavelength of the drift wave, which would be seen in the ionosphere as an increasing azimuthal distance between successive patches in a sequence of activations.

Due to the negative and positive charges in the dipole structure of the drift waves, the FACs associated with the DAB mode should be filamentary. Hoffman et al. (1994) found that, during the substorm EP, while there was sufficient net upward FAC for electrojet closure, the fine structure of the FACs was indeed very filamentary. Either sign of FAC can be encountered locally. Evidence showing the filamentary FAC structures and the increasing wavelength of the drift wave can be found from the delay times between the red-line $(630 \mathrm{~nm})$ and $\mathrm{H}_{\beta}$ blue-line ( $486.1 \mathrm{~nm}$ ) peaks measured by the Gillam MSP in our event. Bin 7 of the MSP $486.1 \mathrm{~nm}$ emission is located $\sim 0.5^{\circ}$ north of Gillam station and shows the highest intensity of all the 17 bins during the interested event interval. The average intensity of the $630 \mathrm{~nm}$ emission in bins 7 and 8 of the $630 \mathrm{~nm}$ emission (bin 8 is centered above the station and bin 7 is $\sim 1^{\circ}$ north of it) occurs at the conjugate position to the $486.1 \mathrm{~nm}$ emission in bin 7 . We shall associate the red-line and blue-line emissions with upward and downward FAC filaments, respectively, originating in the alternating electric charge structure of the drift waves. The red-line emission arises from the electron precipitation and is generally associated with upward FACs, while the blue-line emission arises from the proton precipitation and associated downward FACs. Figure 14 shows, in the left panel, the time variations of the intensities of the two emission lines. The 
right panel is obtained by matching the five peaks in the red line with the increasingly retarded peaks in the blue line. The fourth peak of each line is broad, making it difficult to assign a precise time to the blue line, so the center of the flat-topped peak was chosen. It is clear that the red line and blue line peaks occurred alternatively, with the red line peaks preceding. Such an ionospheric signature is consistent with the passage of a series of eastward-propagating "trigger waves" in the inner plasma sheet. It is also interesting to note that there is almost a linear increase with time in the delay of the blue line peaks with respect to the red line peaks (the dotted line at $45^{\circ}$ slope would be the line along which the peaks would occur if they were simultaneous), which implies that the negative and positive charges within the drift wave became separated by greater and greater distances. The possible reason for such an increase is exactly the one we used to explain the increasing azimuthal separation of the discrete intensified patches observed during each auroral activation, namely that the successive dipolarizations of the NGOPS magnetic field led to increasing energization and thus increasing curvaturegradient drift speed of the particles at NGOPS. As a result, the negative and positive charges within the drift wave would be separated by increasingly greater distances, causing the progressively greater time delay over the ground observation point between the passage of the upward FAC leg and the downward FAC leg within a "trigger wave", or equivalently, causing the increasing time lag between the red-line emissions and the $\mathrm{H}_{\beta}$ emissions.

The radar electric field observations are also consistent with the existence of the "trigger waves". The "trigger wave" should contain an eastward polarization electric field sufficiently strong to overwhelm the background westward electric field in the plasma sheet. That eastward electric field should also map to the ionosphere and lead to poleward convective plasma flows. The oscillating polarization electric field $\delta \mathbf{E}$ associated with the drift waves was found to have a typical oscillation period of 60-90 s and was spatially confined. This electric field would produce very little effect on the convection maps (Figs. 4-6) based on the potential mapping procedure (Ruohoniemi and Baker, 1998), because that the procedures employs averaging both in time and space. Therefore the convection map should show mainly the mean ambient electric field. However, the VLOS observations from individual radar beams can be used to achieve more time resolution, because the time interval between adjacent beams is 7 seconds.

The SuperDARN VLOS values for the Saskatoon radar are plotted in Fig. 15 for beams 1 through 6. Magnetic north is about midway between beams 3 and 4 , so the six beam directions are no more than $\sim 10^{\circ}$ from magnetic north (recall that the beams are $\sim 3.24^{\circ}$ apart) at latitudes $<70^{\circ}$ MLAT. The unwanted, low elevation angle echoes from the $E$ region echoes can be excluded by using the Saskatoon radar elevation angle observations obtained from the radar interferometer mode. The Rabbit Lake magnetometer is selected for the detection of the Pi2 bursts because it is located near the center of the chosen radar beams. Different symbols are used
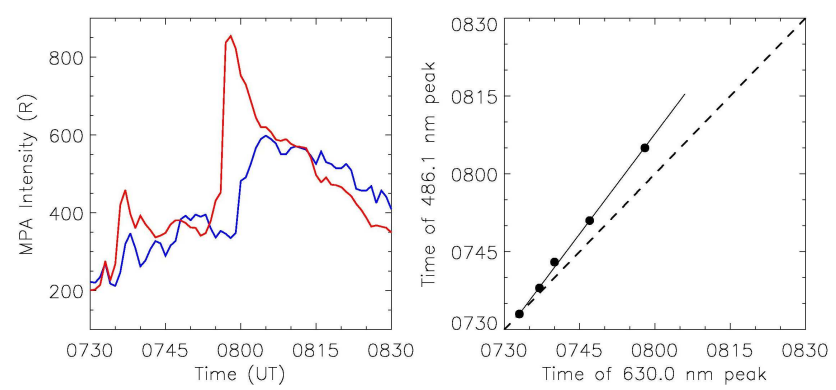

Fig. 14. Left panel shows a plot of the Gillam MSP observations of $\mathrm{H}_{\beta}$ emissions (bin 7) and red-line emissions (average of bin 7 and 8 ) versus time, while the right panel shows the time delays between the red-line and $\mathrm{H}_{\beta}$ emission maxima.

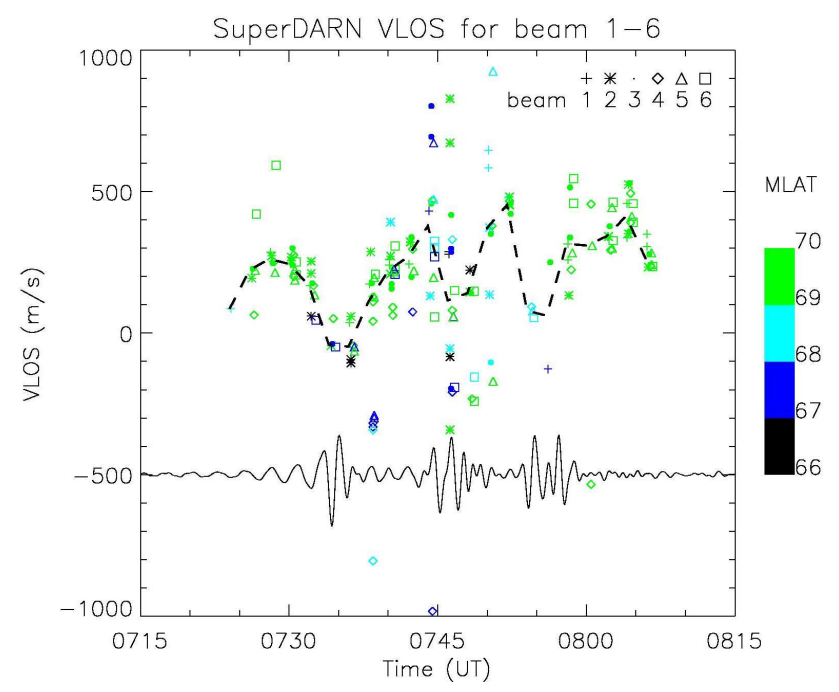

Fig. 15. A plot of the Saskatoon radar VLOS on beams 1 to 6 and the Pi2 activity. The dashed line joins the median value (over the 6 beams) of the velocities observed during each 2-min scan, in the magnetic latitude range $66^{\circ}-70^{\circ}$. Positive velocities denote westward electric field, while negative velocities denote eastward field.

for data from each of the beams. In effect, the Doppler lineof-sight velocity (VLOS) so measured is nearly the magnetic north-south component of the convection velocity. A positive VLOS value indicates that the flow is towards the radar and thus associated with westward electric field, while a negative VLOS value indicates that the flow is away from the radar and thus associated with an eastward electric field. For this analysis, the data were deliberately limited to the range cells at the lower latitudes where the Pi2 pulsations occurred. Although the radar echo occurrence was low in this region and there was some spread in the data, a clear trend can be seen. The overall VLOS was dominantly positive, implying a westward electric field, but some negative VLOS values appeared during the development of each Pi2 burst. In order to better illustrate this trend, the median value of all the Doppler velocities for each two-minute scan was determined, and these median values were joined by a dashed line. In the plot, the 
median VLOS values exhibit three clear minima which correspond exactly with the three maxima of the Pi2 wave trains. There is an obvious tendency toward eastward electric fields at the time of each Pi2 pulsation. Since the Pi2s were the manifestation of the bouncing Alfvén waves, we can conclude that such bouncing Alfvén waves and the related energy transfer between the magnetosphere and the ionosphere were closely associated with a westward-to-eastward turning of the magnetospheric electric field. This result is totally consistent with the CRRES observations that eastward electric field excursions inside the "trigger waves" lead to substorm expansions (Erickson et al., 2000).

\section{Conclusion}

In this paper, the two-dimensional optical auroral structure of a substorm event on 9 October 2000, has been studied using NASI, radar, magnetometer, riometer and MSP data. A sequence of three magnetic and optical auroral activations was found during the event. The first two activations were weak and characteristic of pseudobreakups, while the last and strongest activation corresponded to a substorm EP. All three activations originated close to midnight, but evolved progressively eastward in the form of, firstly, a series of azimuthally-spaced patches appearing successively from midnight toward east, similar to the AAF observations by Elphinstone et al. (1995), and secondly, an overall expansion and enhancement of the auroral luminosity between those patches. Most of the dynamic auroral and convection signatures were observed in the postmidnight sector. We have shown that the auroral activations could be readily explained in terms of the development of drift waves and DAB instabilities in the NGOPS. The azimuthally-spaced auroral patches observed by the NASI during each of the activation were the manifestation of the growing drift wave structures. The MSP blue- and red-line observations at Gillam give further evidence of the dipole structure and the increasing wavelength of the drift waves during the event sequence, which is likely the consequence of successive magnetic dipolarizations in the NGOPS. The SuperDARN line-of-sight velocity (VLOS) measurements revealed the development of eastward electric fields within each Pi2 burst interval, consistent with the CRRES observations that the growing eastward electric fields inside the "trigger wave" leads to a substorm expansion (Erickson et al., 2000).

Acknowledgements. The SuperDARN radar operations at Saskatoon and the NORSTAR operations are supported by grants from the Natural Sciences and Engineering Research Council of Canada (NSERC) and the Canadian Space Agency (CSA). CANOPUS MSP, riometer and magnetometer operations are funded by the CSA. We acknowledge the scientific management efforts of D. André for the Saskatoon SuperDARN radar and of F. Creutzberg, D.Wallis, and B. Jackel for the CANOPUS and NORSTAR instruments. We also thank NOAA National Geophysical Data Center for supplying the GOES satellite data.

Topical Editor M. Pinnock thanks T. Yeoman and Z. Pu for their help in evaluating this paper.

\section{References}

Akasofu, S.-I.: The development of the auroral substorm, Planet. Space Sci., 12, 273-282, 1964.

Baker, K. B. and Wing, S.: A new magnetic coordinate system for conjugate studies at high latitudes, J. Geophys. Res., 94, 91399143, 1989.

Edwards, D. N. and Rusbridge, M. G.: Experimental and theoretical study of drift-waves in a quadrupole: II-radial eigenfuctions, Plasma Phys., 24, 789-800, 1982.

Elphinstone, R. D., Hearn, D. J., Cogger, L. L., Murphree, J. S., Singer, H., Sergeev, V., Mursula, K., Klumpar, D. M., Reeves, G. D., Johnson, M., Ohtani, S., Potemra, T. A., Sandahl, I., Nielsen, E., Persson, M., Opgenoorth, H., Newell, P. T., and Feldstein, Y. I.: Observations in the vicinity of substorm onset: Implications for the substorm process, J. Geophys. Res., 100, 7937-7969, 1995.

Erickson, G. M., Maynard, N. C., Burke, W. J., Wilson, G. R., and Heinemann, M. A.: Electromagnetics of substorm onsets in the near-geosynchronous plasma sheet, J. Geophys. Res., 105, 25 265-25 290, 2000.

Greenwald, R. A., Baker, K. B., Dudeney, J. R., Pinnock, M., Jones, T. B., Thomas, C., Villain, J.-P., Cerisier, J.-C., Hanuise, C., Hunsucker, R. D., Sofko, G. J., Koehler, J., Nielsen, E., and Pellinen, R.: DARN/SUPERDARN, A Global View of the Dynamics of High-Latitude Convection, Space Sci. Rev., 71, 761-796, 1995.

Hoffman, R. A., Fujii, R., and Sugiura, M.: Characteristics of the field-aligned current system in the nighttime sector during auroral substorms, J. Geophys. Res., 99, 21 303-21 325, 1994.

Ivanov, V. N. and Pokhotelov O. A.: Flute instability in the plasma sheath of the Earth's magnetosphere, Sov. J. Plasma Phys., 13, 833-842, 1987.

Ivanov, V. N., Pokhotelov, O. A., Feygin, F. Z., Roux A., Perraut S., and Leko D.: Balloon instability in a terrestrial magnetosphere with irregular pressure and a finite $\beta$, Geomagn. Aeron., 32, 211216, 1992.

Jackel, B. J., Creutzberg, F., Donovan E. F., and Cogger L. L.: Triangulation of auroral red-line emission heights, Proc. Atoms. Studies by Optical Methods, 1-4, 2003.

Kan, J. R.: A global magnetosphere-ionosphere coupling model of substorms, J. Geophys. Res., 98, 17 263-17 276, 1993.

Liang, J., Sofko, G. J., Donovan, E. F., Watanabe, M., and Greenwald, R. A.: Convection dynamics and driving mechanism of a small substorm during dominantly IMF $B_{y}+, B_{z}+$ conditions, Geophys. Res. Lett., 31, L08803, doi:10.1029/2003GL018878, 2004.

Liou, K., Meng C.-I., Lui A. T. Y., Newell P. T., and Wing S.: Magnetic depolarization with substorm expansion onset, J. Geophys. Res., 107(A7), doi:10.1029 /2001JA000179, 2002.

Liu, W. W.: Physics of the explosive growth phase: Ballooning instability revisited, J. Geophys. Res., 102, 4927-4931, 1997.

Lopez, R. E. and Lui, A. T. Y.: A multisatellite case study of the expansion of a substorm current wedge in the near-Earth magnetotail, J. Geophys. Res., 95, 8009-8017, 1990.

Lui, A. T. Y. and Kamide, Y.: A fresh perspective of the substorm current system and its dynamo, Geophys. Res. Lett., 30(18), 1958, doi:10.1029/2003GL017835, 2003.

Lui, A. T. Y., Chang, C.-L., Mankofsky, A., Wong H.-K., and Winske, D.: A cross-field current instability for substorm expansions, J. Geophys. Res. 96, 11 389-11 401, 1991.

Lui, A. T. Y.: Current controversies in magnetospheric physics, Rev. Geophys., 39, 533-563, 2001. 
Lui, A. T. Y.: Current disruption in the Earth's magnetosphere: Observations and models, J. Geophys. Res., 101, 13 067-13 088, 1996.

Maynard, N. C., Burke, W. J., Basinska, E. M., Reickson, G. M., Hughes, W. J., Singer, H. J., Yahnin, A. G., Hardy, D. A., and Moser, F. S.: Dynamics of the inner magnetosphere near times of substorm onsets, J. Geophys. Res., 101, 7705-7736, 1996.

Ohtani, S. and Tamao, S.: Does the ballooning instability trigger substorms in the near-Earth magnetotail? J. Geophys. Res., 98, 19369-19379, 1993.

Olson, J. V.: Pi2 pulsations and substorm onsets: A review, J. Geophys. Res., 104, 17 499-17 520, 1999.

Penman, J. M., Hargreaves, J. K., and McIlwain, C. E.: The relation between 10 to $80 \mathrm{keV}$ electron precipitation observed at geosynchronous orbit and auroral radio absorption observed with riometers, Planet. Space Sci., 27, 445-451, 1979.

Pu, Z. Y., Korth, A., Chen, Z. X., Friedel, R. H. W., Zong, Q. G., Wang, X. M., Wong, M. H., Fu, S. Y., and Pulkkinen, T. I.: MHD drift ballooning instability near the inner edge of the near-Eearth plasma sheet. J. Geophys. Res., 102, 14 397-14 406, 1997.

Roux, A., Perraut, S., Robert, P., Morane, A., Pedersen, A., Korth, A., Kremser, G., Aparicio, B., Rodgers, D., and Pellinen, R.: Plasma sheet instability related to the Westward Traveling Surge, J. Geophys. Res., 96, 17 697-17 714, 1991.

Ruohoniemi, J. M. and Baker, K. B.: Large-scale imaging of highlatitude convection with Super Dual Auroral Radar Network HF radar observations, J. Geophys. Res., 103, 20 797-20 811, 1998.

Samson, J. C., MacAulay, A. K., Rankin, R., Frycz, R., P., Voronkov, I., and Cogger L. L.: Substorm Intensifications and Resistive Shear Flow Ballooning Instabilities, in Proc. ICS-3, edited by E. J. Rolfe and B. Kaldeich, 399-404, ESA SP-389, Versailles, 1996.
Schlegel, K. and St-Maurice, J.-P.: Anomalous heating of the polar E-region by unstable plasma waves, J. Geophys. Res., 86, 1447$1452,1981$.

Southwood, D. J. and Kivelson M. G.: Charged particle behavior in low-frequency geomagnetic pulsations, 2. Graphical approach, J. Geophys. Res., 87, 1707-1710, 1982.

Southwood, D. J. and Kivelson M. G.: Magnetospheric interchange instability, J. Geophys. Res., 92, 109-116, 1987.

Stoker, P. H., Mathews, M. J., and Scourfield, M. W. J.: Coordinated measurements of auroral light intensities and riometric radio-wave absorption, Geophys. Res. Lett., 23, 641-644, 1996.

Stoker, P. H., Mathews, M. J., and Scourfield, M. W. J.: cosmic radio noise absorption related to structures in auroral luminosity, J. Geophys. Res., 102, 7439-7447, 1997.

Tsyganenko, N. A.: A magnetospheric magnetic field model with a warped tail current sheet, Planet. Space Sci., 37, 5-20, 1989.

Wild, J. A. and Yeoman, T. K.: CUTLASS HF radar observations of high-latitude azimuthally propagating vortical currents in the nightside ionosphere during magnetospheric substorms, Ann. Geophys., 18, 640-652, 2000,

\section{SRef-ID: 1432-0576/ag/2000-18-640.}

Yeoman T. K. and Wright, D. M.: ULF waves with drift resonance and drift-bounce resonance energy sources as observed in artificially-induced HF radar backscatter, Ann. Geophys., 19, 159-170, 2001,

SRef-ID: 1432-0576/ag/2001-19-159.

Yeoman, T. K., Lühr, H., Friedel, R. W. H., Coles, S., Grandé, M. Perry, C. H., Lester, M., Smith, P. N., Singer, H. J., and Orr, D.: CRRES/Ground-based multi-instrument observations of an interval of substorm activity, Ann. Geophys., 12, 1158-1173, 1994,

SRef-ID: 1432-0576/ag/1994-12-1158. 